REVISTA CHILENA DE LITERATURA

Abril 2010, Número 76, 223 - 235

\title{
RITOS DE PASO PARA LA PUESTA EN ESCENA DEL RABINAL ACHI O DANZA DEL TUN*
}

\author{
Patricia Henríquez \\ Universidad de Concepción \\ pathenriquez@udec.cl
}

Palabras Clave: teatro, religiosidad, escena, fiesta, comunidad.

KEY WORDS: Theatre, religiousness, scene, festivity, community.

El Rabinal Achi o Danza del Tun es una obra fundacional del teatro latinoamericano que se pone en escena hasta el día de hoy en Rabinal de Guatemala, en el marco de una fiesta religiosa popular que en tanto tal, genera reconocimiento en la comunidad, subvirtiendo festivamente su funcionamiento normal durante más de una semana. La fiesta revela en todo su esplendor la "costumbre guatemalteca" (Rupflin 27, 56), es decir, esa religiosidad que si bien hace visible la imposición, destrucción y prohibición ejercida por figuras representativas del poder europeo del período de Conquista y Colonia, no deja de mostrar las modalidades de resistencia y apropiación ejercidas desde antaño por los antepasados indígenas y restauradas por las generaciones posteriores.

El Rabinal Achi es teatro en tanto pone en escena, ante otros, relaciones de poder del mundo indígena a través de una composición de danza en ronda que, figurada simbólicamente con los cuerpos de los actores en escenarios al aire libre, traza una historia antigua de liberación, inscrita en el esquema religioso maya y en una de las prácticas más controvertidas e importantes en el marco de la celebración de sus fiestas religiosas, el rito sacrificial del animal humano.

El Rabinal Achi es también rito y en este sentido supone una práctica operativa en el aquí y ahora de la escena guatemalteca, su despliegue continuo desde hace ochocientos

* Proyecto núm.11070076: “Teatro Indígena Prehispánico”, financiado por el Fondo Nacional de Ciencia y Tecnología, Fondecyt. Investigador responsable: Patricia Henríquez Puentes. 
años, exceptuando los momentos de censura, crea y recrea un sistema de conceptos, de nociones e incluso, tal como lo afirma Carrió en relación con la escena ritual contemporánea, crea y recrea intuiciones de conocimiento (53). Esta obra opera hasta el día de hoy como vía de reforzamiento e intensificación de la experiencia comunitaria; en su puesta en escena convergen potenciados distintos lenguajes artísticos, anticipando imaginariamente, como lo señala Escobar en relación con las celebraciones rituales, la síntesis de la cultura (57). Allí confluyen danza, música y poesía, es decir, flor y canto, arte plumario, máscaras, vestuario, tejidos y cerámica, estos últimos despojados de sus funciones subsistenciales básicas para referir a la escena ritual.

Como síntesis cultural, el Rabinal Achi ha ajustado sus formas al máximo para hacer sentido en la comunidad y conjurar tiempos lejanos en los que el arte proponía una imagen del conjunto social, aseguraba su cohesión y avalaba su reproducción (Escobar 126). De ahí que cuando el espectador occidental viaja a Guatemala a ver esta obra fundacional sobreviene una profunda extrañeza frente a unos lenguajes escénicos modalizados según una poética que, tal como lo he referido en escritos anteriores, revela el poder operatorio desencadenado por/en la vivencia escénica, en la cual el arte impregna todas las acciones de la comunidad, instaurando una nueva realidad, la que a su vez permea dinámicamente la obra artística (Henríquez, "De la escena" 79). Los actores, verdaderos depositarios de un saber social, de una forma de interactuar con los espectadores y de una retórica corporal arcaica, restauran en el espacio guatemalteco contemporáneo, gestos, movimientos, danzas, textos y armonías musicales que recuerdan a la comunidad ese otro tiempo ancestral, que existiendo o no, reafirma sus creencias.

El Rabinal Achi se pone en escena en Rabinal de Guatemala el 24 y 25 de enero de cada año según unas pautas que, desde el siglo XIII, se reiteran y al mismo tiempo se reinventan, ante los ojos de Dios y de los hombres, tal como lo señala Grotowski en relación con el performer indígena (Grotowski 4-5). Es importante señalar que lo que se restaura hoy en Rabinal de Guatemala es una partitura de acciones que cita otra antigua, en la que es posible identificar ciertas cualidades y principios básicos del cuerpo humano en movimiento que, en tanto mantienen su vigencia, resultan contemporáneos (Escobar 18). He señalado en otros textos que es factible suponer que la obra ha sido resignificada a través de la adquisición directa, es decir, a través de la imitación y repetición de unos movimientos corporales que reconstruyen conductas reales de los antiguos mayas (Henríquez, Teatro maya 11). Este proceso ha sido dirigido por cada uno de los Directores y Dueños ${ }^{1}$ de la obra que desde el siglo XIII han oficiado como tales y por los integrantes más antiguos del elenco.

El guión corporal del Rabinal Achi dispone los cuerpos en columna y en movimiento de serpentina, con un bailador que guía el recorrido, en un trayecto que culmina en tres

1 El Director y Dueño del Rabinal Achi o Danza del Tun es el que tiene la responsabilidad de custodiarla y guardarla, lo que no supone la apropiación privada del objeto artístico, como si fuera una mercancía, sino su tutela, su protección. Profundizo en esta dimensión de la puesta en escena de la obra en un estudio de pronta publicación. 
rondas que en su conjunto componen una sola. Las rondas, trazadas contra las manecillas del reloj, están "formadas de acuerdo con la relación de jerarquía entre los personajes" (Álvarez 47). Durante la secuencia completa, el movimiento de los cuerpos se caracteriza en general por un ritmo lento, en el que es posible distinguir un enfoque espacial flexible, en un flujo dirigido hacia el centro de las corporalidades, flujo enfatizado por leves movimientos de brazos y pies. Señala Álvarez que esta danza se ajusta a patrones coreográficos tradicionales de raigambre indígena de los cuales no existen sistemas de notación específicos.

Los antecedentes más remotos del Rabinal Achi, en tanto teatro danzado, se encuentran en el Popol Wuj, libro sagrado en el que figuran danzas diversas que, en tanto representaciones simbólicas de escenas en las que interactúan animales y héroes míticos, constituyen referentes importantes de la teatralidad de las culturas mayas y del teatro latinoamericano. Es importante señalar que también existen otros antecedentes danzarios que seguramente han influido en la coreografía de la obra en estudio, antecedentes correspondientes al período de Conquista y Colonia, a los que en esta oportunidad no me voy a referir.

En el capítulo titulado "He aquí entonces su memoria, la muerte de Junajpu e Xbalamke", del Popol Wuj, estos héroes que han resucitado y se han vestido como pordioseros, "parecían pordioseros", vencen a los Señores de Xibalbá a través de la ejecución de cinco bailes, cuatro de los cuales suponen la "transformación" del cuerpo humano en cuerpo animal: baile del pujuy o lechuza, de la comadreja, del armadillo, del ciempiés ${ }^{2}$ y de zancos. Señala Megged que el baile en el Popol Wuj equivale a una estrategia para el triunfo (mágico) sobre el enemigo. Esta estrategia hace uso de la representación simbólica de ciertos animales, residentes en las profundidades o en la noche, con el objeto de percibir los poderes de los mismos en esta lucha mágica contra los Señores de Xibalbá, Señores del inframundo, de la oscuridad y de la muerte (Megged 296, 307). Los héroes bailan y con ello hacen bailar a los Señores del inframundo, sin que éstos se percaten de lo que ocultaba su apariencia de pordioseros.

El vestuario de pobre y, por lo tanto, la contraposición entre apariencia y contenido, fondo y forma, es uno de los elementos míticos comunes a distintas culturas. El andrajoso aspecto exterior, evidencia de la pobreza implícita en la apariencia, supone el llamado a vencer la opacidad de las barreras de la apariencia, hacerla transparente y descubrir al contrario real (Megged 298).

Me he detenido en esta reflexión sobre el relato mítico porque aporta a poner en perspectiva aquellos aspectos de la puesta en escena del Rabinal Achi que, a los ojos de

${ }^{2}$ En el baile del ciempiés uno de los bailadores se pone una daga en la boca, mientras todos danzan con unas carátulas, dando vueltas alrededor a tono de conchas de galápagos. Popol Wuj (Guatemala: Cholsamaj, 2008), 116 Nota $\mathrm{N}^{\circ} 175$. Reflexiono sobre el proceso a través del cual los actores se "transforman" en las figuras representadas, especialmente en animales, en el texto titulado "De la escena ritual a la teatral en una obra de teatro indígena prehispánico: Rabinal Achí o Danza del Tun”. Revista Chilena de Literatura 70 (2007): 79-108. 
los espectadores extranjeros, pueden parecer profundamente extraños y en algún sentido, pobres en apariencia. Me refiero específicamente a una técnica artística que, poniendo en signo una realidad que nos es ajena y frente a la cual es difícil experimentar la ilusión de lo verdadero y la verdad de la ilusión (Pavis 243,246), refuerza e intensifica la experiencia comunitaria, favoreciendo el despliegue de las identidades de los pueblos mayas, es decir, de los discursos, prácticas y posiciones diferentes que los han construido hasta el día de hoy, en un constante proceso de cambio y transformación (Hall y Du Gay 17).

El Rabinal Achi fue puesto en escritura alfabética, durante el siglo XIX, por una figura colonial europea, vinculada a la institución iglesia católica, específicamente por el cura párroco del pueblo de San Pablo de Rabinal, Brasseur de Bourbourg (Henríquez, Teatro maya 80, esc. 78) Éste, apoyado por Bartolo Zis, actor, director y dueño de la obra hasta 1825; y por Vicente Tecú, ayudante de capilla (Sacor 13), lo transcribió al quiche y luego al francés, desencadenando con esto un proceso de construcción de sentido que fijó en escritura aquello que había sido conservado por tradición oral, es decir, trasladó un texto desde una de sus actualizaciones efímeras a "una versión definitiva", concepto ajeno a las culturas orales (Lienhard 10) y por sobre todo, a la naturaleza del arte teatral. Lo anterior dio como resultado, entre otras cosas, la imposición de un ritmo lineal a la narración (Gruzinski 98) y la intervención en algunas de las formas características de la producción discursiva de los pueblos mayas. El proceso de puesta en escritura además redujo el texto, operación que, si bien es inevitable a toda traducción, como así mismo lo es la interpretación (Eco, Decir casi 119, 208), implicó la puesta en funcionamiento de supuestos ideológicos sobre los pueblos indígenas ${ }^{3}$, vigentes explícita o implícitamente desde el siglo XVI. Por ejemplo, la convicción de que estos territorios y pueblos necesitaban ser dominados, preconcepto según el cual los misioneros y letrados españoles del siglo XVI se autodesignaron cronistas dedicados a "poner en forma coherente los relatos que, según algunos de ellos, los amerindios narraban de manera totalmente incoherente" (Mignolo 197).

De modo similar a como ocurrió con gran parte del legado cultural de los pueblos indígenas y de las formas de conservar su pasado, basadas en la supremacía de lo oral de la palabra y apoyadas en sistemas de escritura no alfabéticos, la obra fue objeto de lo que Mignolo ha denominado "colonización de la memoria". Este proceso, según el investigador, se manifestó en el acto de ignorar la producción intelectual y cultural de las comunidades colonizadas, o bien en reconocerlas y aun valorarlas, convirtiéndolas en objeto descrito y analizado por medio de los tipos discursivos empleados en la comunidad colonizadora (Mignolo 191-219).

${ }^{3}$ Said señala que ni el imperialismo ni el colonialismo son simples actuaciones de acumulación y adquisición. Ambos se encuentran soportados y a veces apoyados por impresionantes formaciones ideológicas que incluyen la convicción de que ciertos territorios y pueblos necesitan y ruegan ser dominados, así como nociones que son formas de conocimiento ligadas a tal dominación: el vocabulario de la cultura imperialista clásica está cuajada de palabras y conceptos como "inferior", "razas sometidas", "pueblos subordinados", "dependencia", "expansión" y "autoridad" (44). 
En 1862, en París, la obra fue publicada en edición bilingüe, quiché-francés, en la Collection de documents dans les lagues indigénes (Arrom 14). En 1928, George Raynaud hizo una nueva traducción al francés, a partir de la cual Luis Cardoza y Aragón escribió en 1930 la primera versión en español, titulándola El Varón de Rabinal, versión que publicó en los Anales de la Sociedad de Geografia e Historia de Guatemala, Año $\mathrm{V}$, tomo VI, núms. 3 y 4 . Arrom señala que la edición más conocida de la obra data de 1955, publicada por la Universidad Nacional Autónoma de México (Arrom 14).

He señalado en comunicaciones anteriores que el traslado desde la oralidad a la escritura de textos teatrales indígenas prehispánicos supuso un proceso de recognición (Merleau-Ponty 307), de reinterpretación y reconstrucción (Said, Orientalismo 219) de textos, verdaderos tejidos de citas provenientes de culturas en interacción ${ }^{4}$ (Barthes 69), conservados a través de tradición oral y por sobre todo, escritos con los cuerpos indígenas en el espacio escénico mesoamericano y andino desde aproximadamente el siglo XIII. He señalado además, que desde el siglo XIX ha habido una sucesión de "versiones definitivas" de las obras, en palabras de Lienhard "reducciones" (Lienhard 10 ), verdaderas restauraciones de originales recreados constantemente en un proceso de cambio movimiento incesante a nivel textual y escénico, en el que, sin embargo, es posible distinguir la resistencia en el tiempo de procedimientos fundamentales de un original que ha permeado la cultura letrada (Ostria 71-80).

Pese al proceso que supuso la puesta en funcionamiento de esquemas literarios y juegos del lenguaje de origen y de término diversos, el texto del Rabinal Achí o Danza del Tun revela un predominio de procedimientos del arte de la flor y el canto indígena prehispánico: una fábula que, inscrita en el esquema religioso maya, versa sobre las relaciones de poder al interior del poderío quiche; unos personajes que representan a figuras del poder indígena y a singulares formas de ejercicio de poder, también indígenas; un espacio en el que se desarrollan los acontecimientos que corresponde a una zona de la actual Guatemala, específicamente a Rabinal; una composición de los hechos que revela la estructura propia de las antiguas narraciones orales (Ong 141); y una fuerte presencia en la trama dialógica de procedimientos discursivos característicos de las formas poéticas indígenas prehispánicas tales como paralelismos, difrasismos, redundancias y adjetivaciones, entre otros.

${ }^{4}$ La diversidad cultural, lingüística y política caracterizaba a los pueblos indígenas prehispánicos mesoamericanos y andinos en vísperas del proceso de conquista española. Gruzinski señala en relación con la zona del centro de México (de Michoacán y del Bajío, de la frontera chichimeca en el norte, a la región de Oaxaca en el sur) que todos los pueblos que la habitaban estaban para ese entonces sometidos a incesantes procesos de aculturación como resultado de la convivencia de pueblos antiguos y autóctonos con otros recién llegados al territorio. Estas aculturaciones históricas formaban el telón de fondo de las memorias indígenas. A los múltiples registros económicos, étnicos e históricos se agregaban las variables introducidas por la diversidad de los grupos sociales (Gruzinski, La colonización de lo imaginario 15-17). 
Según antecedentes proporcionados por el antropólogo Carlos García Escobar, en la nota introductoria de la versión de la obra publicada el año 2006, por Hugo Fidel Sacor, el primer registro fotográfico y documentación "para la historia" de la obra fue realizado el año 1955, por el etnógrafo Francisco Rodríguez Rouanet, investigador del Instituto Indigenista Nacional (IIN), ayudado por el que en ese entonces era el Director y Dueño del manuscrito, Esteban Xolop. Es posible señalar entonces, que a partir de mediados del siglo XX los investigadores comenzaron a aproximarse a la puesta en escena de la obra. Cincuenta años más tarde, el Rabinal Achi fue declarado por la UNESCO Obra Maestra del Patrimonio Oral e Inmaterial de la Humanidad, previa presentación de sus antecedentes ante el Ministerio de Cultura y Deportes de Guatemala por un Grupo de Investigación de la Dirección General de Investigación de la Universidad de San Carlos (DIGI) ${ }^{5}$, en el marco del proyecto, "Investigación, rescate y revitalización del Rabinal Achi”, auspiciado conjuntamente por las dos instituciones entre 1986 y 1989 (Sacor 9).

La puesta en escena del Rabinal Achi excede y desborda las distintas versiones del texto. Curiosamente, sin embargo, pese a que quien puso en escritura la obra tuvo la oportunidad de vivir la experiencia de espectador, el texto prácticamente carece de acotaciones escénicas. Vanos fueron para Bourbourg la coreografía de la danza, las máscaras, el vestuario multicolor, los escudos adornados de telas, papeles y plumas de colores a modo de estandartes, los objetos propiciatorios, la música, los ritos de paso, las referencias al Popol Wuj y el marco festivo en el que seguramente se inscribía la escenificación.

En la puesta en escena de la obra que tuvo lugar en enero del año 2009, el vestuario hizo visible las modalidades a través de la cuales los sucesivos Directores y Dueños del Rabinal Achi se han apropiado de los recursos disponibles para restaurar la escena del poder indígena. Esto ha dado como resultado que los personajes masculinos vistan según un modelo que, en palabras de García, refiere a la usanza de las modas españolas de los siglos coloniales. Efectivamente, se trata de un traje de dos piezas, compuesto de saco y pantalón, confeccionado en terciopelo de color verde, rojo y lila, adornado con flecos dorados en las orillas y que lleva sobre los hombros una pequeña capa llamada gola (García, Atlas 152). Este traje, como signo representativo de las sucesivas intervenciones que ha experimentado la puesta en escena, dialoga con otros elementos que portan los actores, referidos a las usanzas indígenas: una corona de plumas de colores, un plato de cobre con dijes colgantes y un hacha de madera con pañuelos de seda de colores que simboliza el instrumento del sacrificio (García, Atlas 153). Por su parte, los personajes femeninos visten a la usanza indígena. Uno de ellos, la doncella U Chug Gug usa una corona en la cabeza, corte y huipil; el otro, Ixoc Muy, representado por un hombre, añade

${ }^{5}$ El grupo de Investigación de la Universidad de San Carlos de Guatemala (DIGI) que presentó los antecedentes de la obra ante el Ministerio de Cultura y Deportes estaba integrado por los antropólogos Silvia Álvarez y Carlos René García Escobar; y por el historiador Hugo Fidel Sacor. 
a su atuendo una máscara. Ambos personajes también portan el hacha del sacrificio (García, Atlas 153).

El elenco del Rabinal Achi instaló la obra en la escena rabinalense durante dos días del mes de enero del año 2009, desplegando una interacción de prácticas simbólicas reveladora de las modalidades de apropiación, pero también de resistencia.

E1 24 y 25 de enero, el elenco realizó dos funciones diarias, tres de las cuales tuvieron lugar en escenarios al aire libre, delimitados como tales solo por los cuerpos de los actores y actrices que danzaron durante dos horas cronológicas y de los músicos que tañeron las trompetas y el tun, en un proceso común de composición ritual y teatral. El día 24 de enero estuve con ellos durante la etapa previa a la primera de cuatro funciones, gracias a la gentileza y hospitalidad de la Sra. María y de su esposo, don José León; y a las gestiones del colega de la Universidad San Carlos de Guatemala, licenciado Carlos Galindo, quien tuvo a bien aceptar la invitación que, por intermedio de Carlos García Escobar, le hice desde Chile, para que se integrara a mi investigación.

Ese 24 de enero, los integrantes del elenco llegaron poco a poco a la casa de don José León, venían a prepararse y a participar de ciertas etapas de los ritos de paso propios del carácter sagrado de las danzas tradicionales de Guatemala ${ }^{6}$; otras etapas de los mismos habían ocurrido diez días antes y ocurrirían días después de las funciones del 24 y 25 de enero. Los ritos de paso en general indican y establecen transiciones entre estados distintos, caracterizados por su estabilidad y recurrencia, culturalmente reconocidas, cuyas fases generales suponen la separación, margen (o limen) y agregación a la comunidad (Turner 103-104).

En el caso de la obra en estudio, los ritos de paso se ejecutan en el marco de una cosmovisión según la cual el principio ordenador que permite la existencia es una combinación de fuerzas invisibles opuestas, que ejercen influencia sobre todo lo existente. López Austin señala que "los pueblos mesoamericanos antiguos y colonizados cuentan con una gran variedad de seres invisibles que no sólo forman parte de su cosmovisión sino también tienen presencia en su vida cotidiana" (Rupflin 27). Estas presencias permanentes y en constante cambio hacen que los límites entre lo sagrado y lo profano se difuminen hasta desaparecer, obligando a una búsqueda sistemática de modalidades de comunicación y devoción sintónicas con la dinámica de las "fuerzas invisibles" que dirigen la conducta individual y colectiva.

${ }^{6}$ Carlos García Escobar señala que los ritos de paso que habitualmente se hacen con motivo de las danzas tradicionales son los siguientes: reunión en la casa de la cofradía del baile ante el altar; ofrecimiento de incienso y prendida de cera (candelas y veladoras); realización de oraciones invocando a los ancestros y bailadores fallecidos; ejecución de ensayos de la danza; velación de trajes y máscaras; ejecución de la danza durante la fiesta patronal ya en el patio de la casa de la cofradía del baile, ya acompañando las procesiones o bien en el atrio de la iglesia y en lugares de espacio abierto; realización de oraciones finales para dar gracias y comprometerse para el año siguiente en los mismos lugares del inicio (La Conversión de San Pablo 65-66). 
Lo sagrado y lo profano se materializa en la actual Guatemala en escenas comunitarias en las que confluyen devoción, intercambio comercial, preparación de alimentos, ingesta de bebidas alcohólicas, interacción social, música de marimbas, y sonido del tun y de las trompetas que acompañan a los elencos de las danzas tradicionales. La confluencia de actos diversos en la misma escena refiere a los núcleos simbólicos de la cultura maya descritos en el Popol Wuj, según los cuales el mundo superior y el inferior deben convivir y alimentarse mutuamente (Megged 197).

Los ritos de paso para el Rabinal Achi suponen distintas escenas y escenarios, en los que es posible distinguir un patrón común de devoción que permite al elenco la restauración de los vínculos con el Ajaw, con los abuelos y otras fuerzas invisibles que los cuidan, custodian, guardan y protegen y ante los cuales los integrantes del elenco retribuyen con veneración y respeto.

Diez días antes de la primera función, los integrantes del elenco subieron siete cerros sagrados con el objeto de solicitar permiso y bendición a las presencias "cuidadoras y dueñas" de esos espacios; con posterioridad, después de la última función, el elenco subió nuevamente a los cerros para realizar nuevas ceremonias de agradecimiento. El día de la presentación todos se reunieron en la casa del Director, por lo menos cuatro horas antes de la puesta en escena, período durante el cual se pusieron en funcionamiento otros ritos de paso.

Cuando llegamos a la casa de don José León ya había algunos actores, unos se encontraban en el espacio de entrada, en cuyo centro se ubicaba un altar con la figura de San Pablo, el santo patrono, acompañado de flores, fotografías de los dueños de casa y de algunos ancestros, unas candelas encendidas, las máscaras que se utilizarían en la obra, cuidadosamente alineadas en el piso a los pies del altar, a los lados de éstas varios incensarios ${ }^{7}$ y en un muro, colgado parte del vestuario y de los tocados que serían utilizados por los actores. Es importante considerar que las fotografías y las máscaras representaban el espíritu de los antepasados, custodios de la conducta de sus parientes vivos.

Para las culturas ancestrales, la muerte, lejos de implicar el fin de la actividad, supone alcanzar el final de un estadio de desarrollo y el término de un ciclo de crecimiento para transitar a otro (Turner 79). En la cultura maya, los ancestros integran el núcleo familiar activamente, custodiando la salud y el bienestar de cada uno de sus miembros. Estos, por su parte, los veneran como autoridades de la tradición y de los valores absolutos y axiomáticos de la sociedad y representantes del bien común (Turner 110). En este caso, los abuelos invocados en lengua quiche eran algunos personajes históricos de la obra, antiguos bailadores y sus difuntos, como así mismo los difuntos de los vecinos de la

${ }^{7}$ El incienso forma parte del protocolo ritual indígena prehispánico. Cuando Balam Ki'tze, Balam Aq'ab, Majuk'utaje e Ik'i Balam descubren el Sol, la Luna y las estrellas se alegran e inmediatamente desenvuelven su incienso. Las variedades de incienso, Mixtam pom, Kawistan pom, Kabawil pom y Porowal pom, son asociadas con los cuatro lados del mundo (Popol Wuj 156. Nota $\mathrm{N}^{\circ} 249$ ). 
comunidad. En palabras de Carlos García Escobar estos actos corresponden a los ritos propiciatorios o rituales de iniciación que, realizados por un sacerdote indígena, abogado, chimán, abuelo, k'ajau o k'jauxel, tienen por objeto bendecir todos los elementos que serían utilizados en la danza, a saber, trajes, instrumentos musicales, máscaras, altares domésticos, flores, candelas, comidas y bebidas rituales, la casa de la cofradía de bailes y las personas participantes (García, Atlas 17).

A continuación del espacio que concentraba el comportamiento ritual de la familia Coloch, se ubicaba otro espacio semiabierto que comunicaba directamente con el patio. Allí se encontraban otros integrantes del elenco reposando o preparando los trajes, instrumentos e incensarios que llevarían más tarde. Inmediatamente después de este espacio, estaba el patio que funcionaba como lugar de confluencia de distintas construcciones operativas para una familia compuesta por don José León, su esposa, la familia de su hijo y varios nietos. En ese espacio se ubicaba una mesa provista de una gran tetera con café guatemalteco, una olla, también de gran tamaño conteniendo un humeante caldo de res, además de otros recipientes provistos de tortillas de maíz, platos y guacales, todo cubierto de coloridos manteles ${ }^{8}$. Sentados junto a la mesa estaba don José León Coloch y un par de actores comiendo, les servía sonriente la Sra. María, quien, junto a dos ayudantes había preparado el bastimento para esa jornada, tal como lo venía haciendo desde la década de 1960.

La Sra. María Xolop ha sido, desde mediados del siglo XX, una de las figuras determinantes para el proceso de conservación y transmisión del Rabinal Achi o Danza del Tun, en tanto la responsable del bastimento, uno de los elementos importantes de los ritos de paso implicados desde antiguo en la presentación de la obra. Ella es la hija de don Esteban Xolop, el que fue su "Director y Dueño" hasta mediados de la década de 1960, período a partir del cual éste inició el proceso de traspaso de la misma a su yerno, don José León Coloch Garnica, esposo de la Sra. María.

Es importante señalar que la obra ha sido desde el siglo XIII un legado patrilineal. Según la entrevista que me concedió don José León en enero del año 2009, el Rabinal Achi no podría haberlo recibido ella, "la Sra. no sabe leer y las cosas son diferentes, esos son trabajos de hombres, es cierto que también como la ley ahorita está valorando la mujer, pero también hay puntos que no puede hacer una mujer..." (Entrevista realizada por Patricia Henríquez, sin editar).

${ }^{8}$ Los pueblos mesoamericanos conciben el cosmos como un plano de cuatro partes, cada una de las cuales está asociada a un color: rojo, blanco, amarillo y negro; y a un tiempo referido al camino del sol. Cada uno de los cuatro colores significaba un espacio, un tiempo, unos dioses, unos astros y un destino (Popol Wuj 105. Nota $N^{\circ} 160$ ) (Rupflin 27). Las culturas ancestrales otorgan un fuerte simbolismo a los colores, verdaderas condensaciones de zonas enteras de la experiencia psicobiológica, que implican la razón y el conjunto de los sentidos, y se hallan afectadas por los grupos de relación primarios. Entre los símbolos primordiales producidos por el hombre están tres de los cuatro colores del cosmos maya, blanco, rojo y negro, los que representan productos del cuerpo humano, cuya emisión, expulsión o producción se encuentran asociados con un incremento de las emociones (Turner 82-101). 
Para la cultura maya quiche, el bastimento, es decir, la comida, no solo satisface una necesidad orgánica, sino también espiritual, es una de las modalidades a través de las cuales se busca suscitar la prodigalidad de Tzuultaq'a, el Dios del Cerro, Dios de lo concreto o figuración de Dios "con nosotros" (Cabarrús 29, 49). Es importante consignar que los quiche veneraban al Viejo Dios de la Tierra, Mam, Mataqtani o Tzultaqa, dueño del cerro y de todos los seres vivientes que lo habitaban (Akkeren 40).

En la sociedad quiche las escenas de preparación e ingesta de comida están ritualizadas, la comida de todos los días se hace con sumo respeto, como asimismo el tipo de conversación que sostienen los comensales durante su ingesta,

Durante varios minutos los interlocutores sólo entrecruzan palabras sobre temas generales, y en el curso de la conversación no se miran a la cara. Máxime si son de diferentes sexos... El tipo de palabras que se oyen a cada momento son: us (está bien), maak'a najye (no hay problema, está bien), chi jo'kan (así es), yaal (de veras), b'antyox re li Dios (gracias a Dios) La tonalidad es muy importante. Al ir terminando el diálogo éste se va convirtiendo en una serie de pequeños murmullos que cada vez se hacen menos perceptibles (Cabarrús 103-104).

En ambas escenas, de preparación e ingesta de la comida, está presente el Tzuultaq'a y además, el mu o muhel, xmuhel, xtyosil, xwankilal, xwinkilal, la sombra, el principio vital o el espíritu consciente que posee todo lo perteneciente al ámbito natural, principalmente lo que proviene de la tierra, por cuanto entre el hombre y lo grande y pequeño del universo existe, desde la cosmovisión maya, una red de relaciones indisoluble. Dice el Popol Wuj que cuando el muhel es alterado en su función y naturaleza, se puede escapar, ocasionando el awas o aku'as, el castigo (Popol Wuj 54). Además de este principio vital, los alimentos, montañas y animales, poseen guardianes o "dueños". Los venados, pájaros, pumas, jaguares, serpientes cascabel y barba amarilla figuran en el libro sagrado maya como los cuidadores y guardianes de los cerros; el maíz, materia con la que fue construido el hombre, es custodiado por cuatro deidades: Ixtoj, "Diosa del día de pago"; Ixq'anil, Diosa del fruto del maíz cuando está listo para ser cosechado; Ixkakaw, Diosa del maíz como moneda y ofrenda; e Ixtziya, Diosa del maíz como producto cocinado y deidad que custodia la comida de maíz (Popol Wuj 79. Nota N¹19-120).

El humeante caldo de res, las tortillas y el café preparados y servidos al elenco ese 24 de enero del año 2009 por la Sra. María, sintetizaron una forma de percibir el mundo según la cual preparar los alimentos y ofrecerlos a los otros constituye una modalidad simbólica de comunión con la divinidad (Códice de Madrid 12, 18), en tanto para la cultura maya estos actos suponen diversas escenas de comunión con cada una de las deidades o fuerzas invisibles que custodian todo lo existente. Así, lo sagrado se hace profano y lo profano se sacraliza en un movimiento dinámico y constante que compromete la reserva formal básica ligada a los núcleos simbólicos de la cultura maya. 


\section{CONCLUSIONES}

El Rabinal Achi se pone en escena el 24 y 25 de enero de cada año, en Rabinal de Guatemala, en el marco de una fiesta religiosa popular, representativa de la "costumbre guatemalteca", en la que confluyen la devoción a Dios, al Santo Patrono, San Pablo; al Ajaw; y a los abuelos, incluidos los héroes míticos que figuran en el Popol Wuj. En este contexto de devoción coexisten además, el intercambio comercial, la preparación de alimentos, la ingesta de bebidas alcohólicas, la interacción social, la música de marimbas y el sonido del tun y de las trompetas que acompañan a los elencos de las danzas tradicionales. Lo sagrado y lo profano confluyen en la misma escena durante más de una semana, refiriendo a los núcleos simbólicos de la cultura maya descritos en el Popol Wuj, según los cuales el mundo superior y el inferior deben convivir y alimentarse mutuamente.

En este marco festivo, singularizado por la difuminación de los límites entre lo sagrado y lo profano, tienen lugar los ritos de paso para la puesta en escena de una obra que opera hasta el día de hoy como vía de recreación, reforzamiento e intensificación de la experiencia comunitaria, en tanto en su puesta en escena convergen potenciados distintos lenguajes artísticos, anticipando imaginariamente una síntesis de la cultura.

Los ritos de paso suponen distintas escenas y escenarios, en los que es posible distinguir un patrón común de devoción que permite al elenco la restauración de los vínculos con el Ajaw, con los abuelos y otras fuerzas invisibles, verdaderas autoridades de la tradición y de los valores absolutos y axiomáticos de la sociedad, representantes del bien común e integrantes activos del núcleo familiar, custodios de la salud y el bienestar de cada uno de sus miembros.

La preparación y el ofrecimiento del bastimento a los integrantes del elenco del Rabinal Achi, constituye uno de los ritos de paso más importantes de la escenificación de la obra, en tanto en él confluye lo sagrado y lo profano. La Sra. María Xolop ha sido, desde la década de 1960, la depositaria de una tradición que supone para la cultura maya quiche la satisfacción de una necesidad orgánica y también espiritual. Ambas escenas, de preparación e ingesta de los alimentos, suponen el contacto con el mu o muhel, la sombra el principio vital o el espíritu consciente que posee todo lo perteneciente al ámbito natural, principalmente lo que proviene de la tierra, por cuanto entre el hombre y lo grande y pequeño del universo existe, desde la cosmovisión maya, una red de relaciones indisoluble.

\section{BIBLIOGRAFÍA}

Álvarez, Silvia. "Danza del Rabinal Achi". Rabinal Achi o Danza del Tun. Guatemala: Subcentro Regional de Artesanías y Artes Populares, 1996.

Arrom, José Juan. Historia del Teatro Hispanoamericano (Epoca Colonial). México, D.F.: Ediciones de Andrea, 1967.

Barthes, Roland. El susurro del lenguaje. Más allá de la palabra y la escritura. Barcelona: Ediciones Paidós Ibérica, 1994. 
Cabarrús, Carlos Rafael. La Cosmovisión Q'eqchi'en el Proceso de Cambio. Guatemala: UCA Editores, 2006.

Carrió, Raquel. "Teatro y ritualidad en la escena cubana actual”. Propuestas escénicas de fin de siglo: FIT 1998. Michigan: Ediciones de GESTOS, 1999. 49-63.

Eco, Humberto. Decir casi lo mismo. Experiencias de traducción. Barcelona: Editorial Sudamericana, 2008.

Entrevista a Don José León Coloch. Realizada por Patricia Henríquez en el mes de enero del año 2009 (sin editar).

Escobar, Ticio. El mito del arte y el mito del pueblo. Cuestiones sobre arte popular. Santiago: Ediciones Metales Pesados, 2008.

García Escobar, Carlos René. La Conversión de San Pablo. El drama y la danza evangelizadores en Guatemala. Guatemala: Centro de Estudios Folklóricos, Universidad San Carlos de Guatemala, 2004.

ed. Atlas Danzario de Guatemala. Guatemala: Editorial Cultura. Dirección General de Arte y Cultura del Ministerio de Cultura y Deportes, 1996.

Grotowski, Jerzy. "El Performer”. Máscara. Cuadernos Latinoamericanos de reflexión sobre escenología. 1 (1989): 4-5.

Gruzinski, Serge. El pensamiento mestizo. Cultura amerindia y civilización del Renacimiento. Barcelona: Paidós, 2007.

La colonización de lo imaginario. México: Fondo de Cultura Económica, 2004.

Hall, Stuart. “Introducción: ¿Quién necesita la ‘identidad'?’. Cuestiones de Identidad. Ed. Stuart Hall y Paul du Gay. Buenos Aires: Amorrortu Editores, 2003.

Henríquez, Patricia. "De la escena ritual a la teatral en una obra de teatro indígena prehispánica: Rabinal Achí o Danza del Tun”. Aisthesis. Revista Chilena de Investigaciones Estéticas 44 (2008): 67-81.

ed. “Teatro maya: Rabinal Achi o Danza del Tun.” Revista Chilena de Literatura 70 (2007): 79-108.

Los Códices. El Códice de Madrid. Codex Tro-Cortesianus. Tz'ib rech Madrid. Guatemala: Amanuense Editorial, 2007.

Lienhard, Martín. "El cautiverio colonial del discurso indígena: Los testimonios". Del discurso Colonial al Proindigenismo. Ensayos de Historia Latinoamericana. Ed. Pinto Rodríguez. Temuco: Ediciones de la Universidad de la Frontera, 1998.

Megged, Nahum. El Universo del Popol Vuh. Análisis psicológico y filosófico del mito quiché. México: Editorial Diana, 1992.

Merleau-Ponty, Maurice. A estructura do comportamento. Trad. Márcia Valéria Martinez de Aguiar. Sao Paulo: Martins Fontes, 2006.

Mignolo, Walter. "La colonización del lenguaje y de la memoria: complicidades de la letra, el libro y la historia”. Discursos sobre la invención de América. Atlanta Ámsterdam: Rodofi, 1992.

Ong, Walter. Oralidad y escritura: tecnologías de la palabra. México: Fondo de Cultura Económica, 1987. 
Ostria, Mauricio. "Literatura oral, oralidad ficticia". Estudios Filológicos 36 (2001): 71-80.

Pavis, Patrice. Diccionario del teatro. Dramaturgia, estética, semiología. Barcelona: Ediciones Paidós, 1998.

Popol Wuj. Trad. Sam Colop. Guatemala: Cholsamaj, 2008.

Rupflin Alvarado, Walburga. El Tzolkin... Es más que un calendario. Guatemala: Editorial Serviprensa Centroamericana, 1999.

Sacor, Hugo Fidel. "Introducción”. Rabinal Achi o Danza del Tun. Guatemala: Dirección General de Investigación. Universidad San Carlos de Guatemala, 2006.

Said, Edward. Cultura e Imperialismo. Barcelona: Editorial Anagrama, 1996. Orientalismo. Barcelona: DeBolsillo, 2004.

Turner, Victor. La selva de los símbolos. España: Siglo Veintiuno Editores, 1999.

Van Akkeren, Ruud. Chi raqan animal tz'aq animal k'oxtun. Rabinal en la Historia. Memoria del Diplomado Cultural. Guatemala: Museo Comunitario "Rabinal Achi", 2005. 
